\title{
Representação da identidade negra na telenovela brasileira ${ }^{1}$
}

\author{
Maria Cristina Brandão de Faria² \\ UFJF \\ cristinabrandao@acessa.com \\ Danubia de Andrade Fernandes 3 \\ UFJF \\ danubia_andrade@hotmail.com
}

\begin{abstract}
Resumo: Por meio da análise das personagens 'Preta' e 'Foguinho', das telenovelas "Da cor do pecado" e "Cobras \& lagartos", respectivamente, ambas de João Emanuel Carneiro, Rede Globo de Televisão, perguntamonos: qual modelo de identidade negra a ficção seriada brasileira está criando e difundindo diariamente? Adotando uma perspectiva crítica focada na emissão, intentamos avaliar contribuições e dívidas da teledramaturgia de nosso país no que tange a representação da identidade negra.
\end{abstract}

Palavras-chave: Telenovela brasileira; identidade negra; representação.

Abstract: This article proposes an analysis of the characters 'Preta' and 'Foguinho', presented, respectively, in "Da cor do pecado" and "Cobras \& lagartos", both soap operas aired on Rede Globo de Televisão and written by João Emanuel Carneiro. Our main question is: what is the black identity model created and spreaded out everyday by the brazilian serial fiction? Adopting a critical perspective, focused in emission, we will try to analyse the faults and contributions of brazilian soap operas, relating to the representation of black identity.

Key-words: Brazilian soap operas; black identity; representation.

\footnotetext{
${ }^{1}$ Trabalho apresentado no VII Encontro de Núcleos de Pesquisa em Comunicação - NP Ficção Seriada

2 Professora titular da Graduação e colaboradora do Programa de Mestrado "Comunicação e Sociedade" da Faculdade de Comunicação Social da Universidade Federal de Juiz de Fora (Facom / UFJF). Doutorada em Teatro pela Universidade Federal do Rio de Janeiro (UNIRIO). Autora de "O grande teatro Tupi do Rio de Janeiro" (Ed. UFJF/TV Panorama, 2005).

3 Jornalista formada, pós-graduada em "Artes, Cultura Visual e Comunicação" e mestranda em "Comunicação e Sociedade" pela Faculdade de Comunicação Social da Universidade Federal de Juiz de Fora (Facom / UFJF).
} 
Resumen: Por medio del análisis de los personajes 'Preta' y 'Foguinho', respectivamente presentados en las telenovelas "Da cor do pecado" y "Cobras \& lagartos", cuyo autor es João Emanuel Carneiro, de la Rede Globo de Televisão, nos preguntamos: ¿cuál sería el modelo de identidad negra que la ficción seriada brasileña está criando y difundiendo a diario? Utilizando una perspectiva crítica, cuyo foco está en la emisión, intentamos evaluar las contribuciones y deudas de la teledramaturgia brasileña a lo que concierne la representación de la identidad negra.

Pallavras-llave: Telenovela brasileña; identidad negra; representación.

Résumé: Par moyen de l'analyse des personnages 'Preta' et 'Foguinho', respectivement des feuilletons "Da cor do pecado" et "Cobras \& lagartos", dont l'auteur est João Emaneul Carneiro, à Rede Globo, nous demandons quel sera le modèle d'identité nègre qui la fiction sérielle brésilienne est en train de fomenter et diffuser tous les jours. Nous utiliserons une perspective critique dont le foyer du problème est l'émission, essayerons évaluer les contributions et dettes del feuilleton brésilien en ce qui concerne la représentation de la identité nègre.

Mots-clés: Feuilleton brésilien; identité nègre; représentation.

\section{Televisão e construção de identidades}

“Antigamente o pelourinho era o pau e o chicote.

Hoje está nos meios de comunicação de massa.

Somos chicoteados a toda hora em nossa autoestima."

Antônio Pitanga ${ }^{4}$

Conforme Stuart Hall, uma mudança estrutural está transformando as sociedades modernas, gerando uma descentração dos indivíduos tanto de seu lugar no mundo social quanto de si mesmos. As concepções de identidade vigoradas até então dão lugar ao sujeito pós-moderno. Ao invés da identidade fixa passamos a possuir uma multiplicidade desconcertante e cambiante de identidades, com as quais nos identificamos temporariamente (HALL, 1999, p.7-13).

\footnotetext{
4 Jornal do Brasil, Super TV, 20 a 26 de julho de 1997, p.5.
} 
Ao encontro da análise de Hall, Zygmunt Bauman considera a identidade como algo negociável e revogável, fruto das decisões que o próprio indivíduo tomar, dos caminhos que percorrer, enfim, conseqüência inescrutável de sua maneira de agir. A identidade como algo a ser inventado, não descoberto. A perspectiva construtivista compreende a identidade como um trabalho de criação de uma individualidade própria e particular, um "eu” singular e único, com possibilidades de realização aparentemente ilimitadas. Cada vez mais essa perspectiva individualista da constituição da identidade ganha espaço, marcando as possibilidades do sujeito de construir-se livremente. Entretanto, como nos lembra João Pissarra Esteves (1999), torna-se preciso repensar o papel da mídia na construção de identidades, uma vez que fazemos parte de uma sociedade midiática e consumista.

Esteves afirma que, diante de uma "vertigem teórica pós-moderna", podemos nos esquecer de que a mídia cumpre funções sociais básicas como a reprodução cultural, a socialização e a integração social dos indivíduos. Essas funções sociais são asseguradas pela mídia, através da ampla oferta que esta dispõe de modelos de pensamento e ação, de quadros simbólicos difundidos e impostos socialmente por processos de imitação e formas ritualizadas. Em outras palavras, a perspectiva pós-moderna pode omitir a capacidade da mídia de produzir "identidades" socialmente úteis, perfeitamente codificadas e estereotipadas, divulgadas nos mais diversos produtos midiáticos. Neste contexto, Esteves nos fala do surgimento de pseudo-identidades:

O nosso tempo não é o do aniquilamento da identidade, mas o da sua saturação: pseudo-identidades luxuriantes produzidas à margem do próprio indivíduo, com o fim de o domesticar, servindo a generalidade dos modelos em circulação (e as suas variações infinitas) como dispositivo e de disciplinamento do corpo social. (ESTEVES, 1999, p.5)

De fato, houve um alargamento do campo de possibilidades para projetos de configuração do indivíduo, uma vez que a perspectiva iluminista de fixidez e imutabilidade da identidade cedeu lugar a uma perspectiva construtivista e fluida. Porém, esse sujeito tem de construir-se sem necessariamente manter a ancoragem nos laços tradicionais, subordinando-se a outros parâmetros _corpo social, mídia, consumo. 
Trata-se, portanto, de um processo ambíguo. Por um lado, confere-se ao sujeito a responsabilidade e a autonomia na construção de suas representações e papéis sociais. Mas, ao mesmo tempo, por meio de uma enorme engrenagem cujo lugar central se daria através dos diversos meios de comunicação, estimula-o a consumir não só para satisfazer necessidades primárias e marcar posições sociais: o consumo passa a ser uma via pela qual o sujeito constrói a si mesmo (ENNE, 2006, p.24). Vale a ressalva, entrementes, que aponta a existência de modos de resistência, subversão e negociação das identidades face aos modelos da sociedade midiatizada e à cultura do consumo.

Neste artigo, especificamente, buscamos mensurar a capacidade da mídia de conformar a identidade, oferecendo aos seus espectadores modelos daquilo que, para ela, significa ser homem ou mulher, jovem ou velho, bem-sucedido ou fracassado, bonito ou feio, desejável ou desprezível. Acreditamos que a cultura da mídia oferece a base sobre a qual muitas pessoas constroem seu senso de classe, de raça e etnia, de nacionalidade, de sexualidade; enfim, ela nos ajuda na construção de nossa identidade e na determinação do que seja o "Outro", o diferente do que somos (KELLNER, 2001).

Mas se a mídia possui esse enorme poder de interferir na construção das identidades do sujeito, oferecendo a base sobre a qual as identificações irão se processar, como nos diz Kellner, ou mesmo produzindo identidades socialmente úteis, conforme Esteves, torna-se necessário analisar um dos seus mais competentes veículos: a televisão. Afinal, não é na televisão que se concentram as publicidades que incitam o consumo? Não é a televisão o suporte que fornece entretenimento, cultura e informação a boa parte do povo brasileiro? Não está este veículo perfeitamente encaixado na rotina política e social de nosso país?

A televisão _e como veremos adiante, a teledramaturgia, não intervém na realidade por meio de uma narrativa desvinculada de um projeto ideológico; ao contrário, almeja construir a realidade. Por isso, a televisão não é o espaço da narrativa do real, mas da construção do real. Sendo essa construção perpassada nitidamente por processos de controle político da realidade que objetivam homogeneizar o coletivo. 
A antiga máxima de que a televisão é uma janela aberta para o mundo, conforma-se na idéia de que os espectadores é que vêem o mundo pela estreita janela da tevê. Neste artigo, objetivaremos a perspectiva crítica. Analisaremos algumas personagens das telenovelas "Da cor do pecado" e "Cobras \& lagartos", ambas exibidas no horário das 19h, pela Rede Globo, para descobrir qual identidade negra a televisão brasileira está construindo e propagando por meio de sua teledramaturgia.

\section{Que negro é esse na novela das sete?}

No contexto brasileiro, a telenovela não é apenas mais um produto da indústria da mídia: trata-se de um dos mais relevantes tanto por sua audiência quanto pela capacidade de pautar a agenda social. Esse produto ficcional difunde discursos a partir dos quais o sujeito negociará a definição de si mesmo e do "Outro", estabelecendo uma hierarquia de valores e concepções muito dependente de influências advindas da mídia.

A telenovela é responsável por elaborar e propagar modelos identitários que serão referência para o espectador, tanto quanto os bordões ou os acessórios usados por um determinado personagem. E diferente da atuação de filmes, espetáculos esportivos ou programas humorísticos, a telenovela é presença diária no cotidiano do brasileiro há quase 50 anos _fato que potencializa sobremaneira seu campo de interferência no imaginário nacional. Podemos dizer que as telenovelas constroem a realidade e, ao mesmo tempo, alimentam-se do real:

A telenovela pode ser considerada, no contexto brasileiro, o nutriente de maior potência do imaginário nacional e, mais que isso, ela participa ativamente na construção da realidade, num processo permanente em que ficção e realidade se nutrem uma da outra, ambas se modificam, dando origem a novas realidades, que alimentarão outras ficções, que produzirão novas realidades. O ritmo dessas transformações passa a ser a questão. (MOTTER, 2003, p.174)

As telenovelas escolhidas para esta análise são da autoria João Emanuel Carneiro5 e foram exibidas pela Rede Globo no horário das 19h _horário que tradicionalmente é reservado para tramas contemporâneas e leves, com núcleo de humor palpitante e enredo fácil. Dificilmente as ficções apresentadas nesse horário

\footnotetext{
5 Vale destacar que "Da cor do pecado" foi escrita por João Emanuel Carneiro, mas teve a supervisão do texto realizada por Sílvio de Abreu.
} 
levantam polêmicas de cunho social relevante ou organizam as pautas de conversação da sociedade. Por isso, "Cobras \& lagartos" e especialmente "Da cor do pecado" apresentam-se como exceções, uma vez que têm proeminência para a História da Teledramaturgia Brasileira por serem as pioneiras no que tange a apresentação do negro como protagonista.

"Da cor do pecado"6 foi exibida de 26 de janeiro a 28 de agosto de 2004 e reprisada em 2007, no "Vale a pena ver de novo", a partir de 7 de maio. Essa telenovela, apesar de ser uma produção do horário das 19h, que como já dissemos tradicionalmente não tem a intenção de levantar polêmicas para a agenda social, conseguiu pautar a discussão do racismo na mídia impressa e nos programas televisivos. Além disso, sua relevância também se deve ao fato de ter sido a primeira produção global a contar com uma protagonista negra.

Não devemos nos olvidar, entretanto, que em 1996, a Rede Manchete exibiu "Xica da Silva", trama na qual Taís Araújo deu vida a primeira protagonista negra da História da Teledramaturgia Brasileira. A personagem era 'Xica', uma escrava inteligente e sedutora, consciente de sua injusta condição social e capaz de enfrentar de forma intrépida seus inimigos preconceituosos. Valorizamos o pioneirismo da Rede Manchete, ainda que em ficção histórico-escravocrata; porém, como analisou Esther Hambúrguer7 a emissora priorizou a beleza da jovem atriz em detrimento de uma campanha mais ousada em torno da negritude, das lutas e dos quilombos8.

Em "Da cor do pecado" a crítica inicia-se no título. Afinal, qual é a cor do pecado? O corpo nu de uma mulher negra, apresentado nos últimos takes da abertura da novela, nos remete a uma possível resposta _a mais óbvia ao espectador médio. Resposta que, vale ressaltar, converge com o senso comum brasileiro que associa a mulher negra à sensualidade, à sexualidade. E ainda, é preciso observar que o título não faz uma pergunta, ao contrário, ele afirma: o negro é a cor do pecado. Reiterando a indagação de Luciene Cecília Barbosa (2004, p.5), questionamos: por que este

\footnotetext{
6 "Da cor do pecado" atingiu picos de audiência de 39 pontos no Ibope, o equivalente a 68\% dos aparelhos ligados. Foi a telenovela com maior audiência no horário das $19 \mathrm{~h}$ desde "Quatro por quarto", de Carlos Lombardi, exibida em 1994 (ÉPOCA, 8 de março, 2004, p.84).

7 Folha de S. Paulo, 18 nov. 1996, Ilustrada, p.4.

8 Mesma sensualidade que ajudou o SBT a conquistar picos de 20 pontos de audiência no horário das 21 horas, quando reapresentou "Xica da Silva", roubando a audiência da global "América", em 2005 (ESTADO DE MINAS, 1 mai. 2005, Caderno TV, p.6-7).
} 
título, no momento em que pela primeira vez na emissora, está estreando uma negra como personagem principal? E o que poderíamos dizer sobre a canção que pontua as imagens da abertura de "Da cor do pecado"?

Da cor do pecado ${ }^{9}$

Esse corpo moreno cheiroso e

gostoso que você tem

É um corpo delgado da cor do pecado

Que faz tão bem

Esse beijo molhado, escandalizado que você deu

Tem sabor diferente que a boca da gente

Jamais esqueceu

E quando você me responde umas coisas com graça

A vergonha se esconde

Porque se revela a maldade da raça

Esse corpo de fato tem cheiro de mato

Saudade, tristeza, essa simples beleza

Esse corpo moreno, morena enlouquece

Eu não sei bem porque

Só sinto na vida o que vem de você

A canção "Da cor do pecado" apresenta uma mulher capaz de desestabilizar, de enlouquecer por sua sensualidade: a mulher do beijo molhado e escandaloso. A música também nos fala de uma suposta "maldade da raça", entendendo essa maldade como a capacidade de seduzir e de perverter a ordem. Outra associação comum ao negro, reiterada na letra, diz respeito ao cheiro da pele negra, como algo distintivo e muitas vezes negativo.

O título "Da cor do pecado", a canção utilizada na abertura, assim como as cenas que a ilustram sugerem e reafirmam a noção de sensualidade da mulher negra associando-a ao pecado carnal. Não por menos, tal título foi repudiado pelo Fórum Permanente de Mulheres Negras Cristãs do Rio de Janeiro sob o argumento que ele reforçaria, no imaginário brasileiro, o estereótipo da negra sensual, "malemolente", erótica e vulgar ${ }^{10}$.

Os discursos racistas inserem-se na cultura brasileira com ares de "naturalidade" o que, num primeiro olhar, impede uma crítica sistemática. Porém, é preciso fixar que estamos lidando com discursos de exclusão intencionalmente

\footnotetext{
${ }^{9}$ Canção de Bororó, interpretada na voz da cantora (negra) Luciana Melo.

10 Informação colhida no site Mundo Negro, 30 jan. 2004, www.mundonegro.com.br
} 
elaborados, que contam com o estímulo do senso comum para serem aplicados nas relações interpessoais e intergrupais. Com referência ao negro, é preciso estar atento ao fato de que a mídia constrói identidades virtuais (ou pseudo-identidades) a partir não só da negação e do recalcamento da identidade negra, como também um saber de senso comum alimentado por uma longa tradição ocidental de preconceitos e rejeições (PEREIRA, 2001, p.211-16; SODRÉ, 1999, p.246).

No que diz respeito ao enredo de “Da cor do pecado", Taís Araújo deu vida à feirante maranhense 'Preta', que traz no próprio nome o orgulho de sua "raça”. 'Preta' desperta a paixão do carioca 'Paco' (Reynaldo Gianecchini), homem de hábitos simples, embora herdeiro de uma grande fortuna. De um lado, uma vendedora de ervas medicinais que representa a sabedoria e simplicidade da cultura popular, de outro, um botânico, representante do mundo acadêmico e da ciência formal. Indivíduos pertencentes a mundos distintos, porém, unidos pelo amor. Um perfeito conto de fadas moderno que terá de superar as investidas das personagens racistas de Giovanna Antonelli, 'Bárbara', a noiva do galã, e do 'doutor Afonso Lambertini', pai de 'Paco', interpretado por Lima Duarte.

Conforme Renata Pallottini (1998, p.35), numa telenovela podem existir conflitos de natureza definitiva (aqueles pertinentes aos protagonistas) e conflitos de natureza provisória (solucionáveis em alguns capítulos). Na História da Telenovela Brasileira, as oportunidades nas quais o racismo ganhou destaque em tramas pósescravocratas, ele apareceu como um conflito de natureza provisória, envolvendo apenas personagens secundários. Por isso, "Da cor do pecado" foi uma colaboração importante para a discussão da identidade negra na teledramaturgia do nosso país, porque pela primeira vez o racismo apareceu como um conflito de natureza definitiva.

A telenovela diária nasce em 1963 e somente 41 anos depois o racismo teria espaço como conflito vinculado aos protagonistas de uma ficção pós-escravocrata. $\mathrm{O}$ que justificaria isso? Para Solange Couceiro (1983, p.75-8), deve-se a uma "necessidade" das telenovelas brasileiras de reafirmar o Brasil como um território livre de preconceitos raciais, e, assim, difundir uma crença na democracia racial. De um modo geral, nossa teledramaturgia tem preterido as questões raciais, apesar de combater outras formas de conservadorismo, como o machismo ou o preconceito 
contra o homossexual, por exemplo. O racismo somente ganha destaque nas telenovelas a partir da década de 1980, embora o fosse com caráter de conflito provisório.

No intento de mensurar a relevância de "Da cor do pecado" para a sociedade brasileira e para a discussão do racismo, traçaremos uma comparação com outra novela na qual também havia um par romântico inter-racial, "Corpo a corpo"11, exibida 20 anos antes. Em “Corpo a corpo”, Zezé Motta encarnava a arquiteta e paisagista 'Sônia Nascimento Rangel', uma perfeita “dama das camélias” por sua resignação. Marcos Paulo vivia 'Cláudio Fraga Dantas', um jovem herdeiro _assim como 'Paco'.

No desenvolvimento do “dramalhão”, 'Sônia' e 'Cláudio' enfrentam uma série de adversidades para ficar juntos, no entanto, a maior delas estava justamente do lado de fora da tela: a reação dividida do público em relação ao amor dos dois.

O ator Marcos Paulo declarou que a sua secretária eletrônica ficou congestionada por recados racistas e impublicáveis, Zezé Motta sentiu o preconceito de forma inversa; as pessoas que a assediavam nas ruas diziam que ela era "uma sortuda por ter fisgado aquele gatão branco” (...). (ARAÚJO, 2004, p.249)

Por sua vez, o casal 'Preta' e 'Paco' não foi rejeitado pelo público e, ao contrário, constituiu um par romântico simpático à audiência. Assim como também em outras produções dos anos 2000 já podemos coletar exemplos de casais interraciais queridos ${ }^{12}$, o que sinaliza um avanço em termos de aceitação social.

“Cobras \& lagartos” foi exibida pela Rede Globo, de 26 de janeiro a 18 de novembro de 2006, às 19h. Essa novela não objetivou trabalhar a questão o racismo entre os seus temas, porém, figura nesta análise, porque um personagem negro, construído para ser secundário e estereotipado, conquistou o carisma da audiência e passou a protagonista.

Os quatro protagonistas "oficiais" de "Cobras \& lagartos" foram interpretados por atores loiros de olhos claros - Carolina Diekman, Henri Castelli,

\footnotetext{
${ }^{11}$ Novela de Gilberto Braga, levada ao ar pela Rede Globo, de 26 de novembro de 1984 a 21 de junho de 1985, na Rede Globo, em horário nobre.

${ }^{12} \mathrm{Na}$ década de 1990, os romances inter-raciais foram aceitos pela audiência e apareceram de forma freqüente na telenovela brasileira, conforme Araújo (2004).
} 
Daniel de Oliveira e Mariana Ximenes. Fato nada excepcional na teledramaturgia brasileira, na qual, salvo raras exceções, os protagonistas são representados por atores cujo padrão de beleza segue moldes europeus, apontando para uma dificuldade de se valorizar a beleza negra e miscigenada de nossa população.

Já o personagem de Lázaro Ramos, 'Foguinho', de loiro tinha apenas o bigode, numa referência estética justificada pelo ator e pelo diretor da trama, Wolf Maia. O personagem, por absurda carência, descolore o bigode para diferenciar-se no meio de tantos outros "zés ninguém" que habitam o Saara. E por que justamente a cor loira? A ironia está no fato desse personagem, criado para ser secundário, ter roubado o brilho dos outros protagonistas (estes sim, loiros de verdade) e conter nas mãos a chave do desfecho da história.

À personagem de Lázaro Ramos garantia-se apenas o estereótipo do malandro engraçado, bem ao estilo coons ${ }^{13}$, descrito por Donald Bogle (apud Araújo, 2004, p.47-51), como podemos ver na descrição da personagem presente no site de divulgação da telenovela:

Ele é o patinho feio da família já que, nitidamente, seu pai prefere os filhos do segundo casamento, e a família toda o considera um perdedor. Mesmo assim, Foguinho gosta de todos e deseja ser aceito, querido e admirado por eles. Mas ele nunca consegue nada que quer: sonha ser um campeão de boxe, mas jamais ganhou uma única luta; quer namorar a linda e ambiciosa Ellen, sua paixão de infância, mas ela não quer saber de pobre. (...) Mesmo assim, Foguinho ainda acredita que um dia, num golpe de sorte, sua vida vai mudar.

No princípio da trama, quando 'Foguinho' era pobre e trabalhava como "homem-sanduíche" no Saara, para seu pai, ele sofria ofensas racistas de sua madrasta e de seus dois meio-irmãos. Considerado feio e "burro", 'Foguinho' representava o negro sem esperança, sem talento e sem amor. Ao apropriar-se indevidamente de uma herança, e tornar-se rico, a situação mudou: a família que o desprezava passou a bajulá-lo e a mulher que ele amava caiu aos seus pés.

Em “Cobras \& lagartos”, 'Foguinho' somente conquista respeito e afeto por intermédio do dinheiro, revelando uma sociedade que aceita o negro na medida de

\footnotetext{
$13 \mathrm{O}$ termo inglês coons é uma abreviatura de racoons, originalmente refere-se a um animal carnívoro noturno, mas, num contexto racista, nos fala de um sujeito desumanizado, preguiçoso, indolente, inativo, amedrontado.
} 
seu “embranquecimento" pela ascensão social. Conforme Dalmer Pacheco (1988, p.76-7), a moral transmitida pela telenovela brasileira é de tolerância para com o sujeito que vem de uma classe social mais baixa ou daquele sujeito excluído quando este, por meio do dinheiro, conquistar um posto entre a elite.

O primeiro passo de 'Foguinho', depois de tornar-se rico, seria buscar aceitação libertando-se dos valores de sua antiga vida e aprendendo a viver sob as regras da elite. Aprender a se vestir, a falar, a comer, enfim, transformar-se em um “Outro”. Porém, 'Foguinho', por sua ingenuidade ou autenticidade, não consegue romper com o passado e, mesmo rico, mantém seus valores suburbanos o que provoca deboche e piedade. Ao contrário dos ternos em cores sóbrias, ele veste-se em tons fortes de azul, vinho ou dourado. Os acessórios discretos e elegantes são substituídos por colares grossos com pingente em forma de cifrão _moda criada para ser brega que ganhou as ruas dos subúrbios brasileiros.

O grande conflito da trama está no fato de 'Foguinho' ter roubado a herança de seu melhor amigo, seu homônimo 'Daniel Miranda' (Daniel de Oliveira). A partir daí, 'Foguinho' oscilará entre os eixos do bem e do mal, prejudicando seus amigos para sustentar sua farsa, mas, ao mesmo tempo, mostrando-se arrependido e capaz de gestos nobres. Nas palavras de seu interprete: "Foguinho é mutante, não pode ser definido como herói ou vilão" ${ }^{14}$. Um personagem complexo, portanto.

O sucesso de 'Foguinho' desmistificou definitivamente um possível preconceito de autores e diretores de telenovela com relação aos atores negros. O argumento seria que o ator negro brasileiro não teria carisma e talento suficientes para encarnar um protagonista (COUCEIRO, 1983, p.76-9).

Não obstante, enquanto a personagem ‘Foguinho' significou um avanço para a afirmação do negro, a personagem de Taís Araújo não caminhou no mesmo ritmo. Taís Araújo interpretou 'Ellen', uma negra atraente e ambiciosa capaz de qualquer coisa para lograr uma ascensão social e vingar a morte de seu pai. Assim sendo, ‘Ellen’ não fugiu muito do estereótipo da “mulata sedutora” e ambiciosa.

14 ISTOÉ, 19. jul. 2006, p.94. 


\section{Considerações finais}

Recentemente, uma enquête da Revista da TV, do jornal O Globo ${ }^{15}$, perguntou a atores e autores da televisão brasileira se eles acreditavam numa maior participação de negros na tevê. Todos os entrevistados, entre eles Taís Araújo e Gilberto Braga, afirmaram que ainda há um longo caminho para a efetiva inclusão do negro na teledramaturgia, ainda que percebam alguns pontos positivos nesse sentido. De fato, apesar de termos nos detido no discurso e no enredo de apenas duas telenovelas, "Da cor do pecado" e "Cobras \& lagartos", analisando poucas personagens, acreditamos que a participação do ator negro na ficção seriada brasileira tem ganhado espaço e suscitado importantes questões nos últimos anos.

Entretanto, ao avaliar a trajetória do ator negro ao longo da História da Telenovela Brasileira, mensuramos o quanto foram inexpressivas as colaborações dessas telenovelas para construção e propagação de uma identidade negra positiva e para lançar o debate do racismo na esfera pública. Neste sentido, voltamos à enquête do jornal O Globo, cujo título era "o sonho da igualdade racial”. A palavra "sonho" já sinaliza aos leitores de que maneira caminha a participação do ator negro na teledramaturgia brasileira e quais as chances concretas de uma efetiva mudança. A igualdade racial na televisão brasileira é um sonho, não um projeto. Um sonho e apenas isso.

Ao investigarmos a trajetória dos atores negros na telenovela brasileira, abastecendo-nos na rica pesquisa de Joel Zito Araújo (2004), averiguamos que a eles se destinaram, em sua imensa maioria, papéis que representavam posições subalternas ou serviçais da sociedade e de segunda classe no que se refere à complexidade dos personagens. A estilização do negro tem sido feita à base de estereótipos impregnados de alusões à sua estética, ligados à sua descategorização social e à sua suposta frouxidão de costumes, como no caso dos malandros, preguiçosos ou bandidos. Com efeito, como nos lembrou Taís Araújo, o aproveitamento do ator negro na telenovela ainda está condicionado à “cor” do personagem e aos papéis que historicamente lhe têm sido reservados na vida em sociedade.

15 O Globo, Revista da TV, p.16, 13 mai. 2007. 
No elenco de uma telenovela, ao ator negro será destinado um personagem para o qual já está previsto a característica étnica. Em outras palavras, um personagem que possa ser indiscriminadamente representado por um negro ou por um branco, o será por um ator branco. Ao ator negro somente lhe cabe o personagem construído como negro. E ainda, personagens, quase sempre, secundários ou descartáveis, interpretando papéis sociais subalternos dentro da estrutura social brasileira.

A discriminação que acomete os atores negros é nivelada conforme a intensidade de seus graus de mestiçagem. Quanto mais traços não-brancos apresentarem, mais facilmente serão vinculados aos estereótipos negativos. Assim sendo, a acentuação de traços negros ou indígenas significa necessariamente a associação do artista a personagens secundários e estereotipados da trama.

Todos eles, portanto, são obrigados a incorporar na televisão a humilhação social que sofrem os mestiços em uma sociedade norteada pela ideologia do branqueamento, em que a acentuação de traços negros ou indígenas significa a possibilidade de viver um terno sentimento racial de inferioridade, e uma consciência difusa e contraditória de ser uma casta inferior que deve aceitar os lugares subalternos intermediários do mundo social. (ARAÚJO, 2006, p.77)

Sendo a telenovela um dos principais agentes de construção e propagação de modelos identitários na televisão brasileira, que tipo de identidade negra estamos permitindo que esse produto midiático construa e solidifique diariamente? A identidade negra não está, na maioria das telenovelas brasileiras, associada ao sujeito sem notoriedade, com papel social insignificante, sem voz e sem carisma? Não se trata, então, de violência racista por meio da ficção seriada?

A violência racista do branco exerce-se, antes de mais nada, pela impiedosa tendência a destruir a identidade do sujeito negro. Este, através da internalização compulsória e brutal de um ideal de Ego branco, é obrigado a formular para si um projeto identificatório incompatível com as propriedades biológicas do seu corpo. Entre o Ego e seu Ideal cria-se, então, um fosso que o sujeito negro tenta transpor, às custas de sua felicidade, quando não de seu equilíbrio psíquico (...). (JURANDIR FREIRE, 1983 apud FIGUEIRA, 1988, p.46)

Neste sentido, louvamos iniciativas como "Da cor do pecado" e até, em certa medida, "Cobras \& lagartos", mas entendemos que a representação da identidade negra precisa alcançar outros patamares. Conflitos racistas, por exemplo, deveriam 
aparecer como tema recorrente das tramas, não apenas vinculado aos vilões, como também nas relações familiares e amorosas, a fim de desmistificar o mito da democracia racial. Por sua vez, aos atores negros poderiam destinar os mais distintos tipos de personagens, representantes de qualquer classe social, atuantes em qualquer atividade profissional. Enfim, reivindicamos, sobretudo, uma maior consciência do papel da telenovela na construção e propagação de uma identidade negra negativa, dócil e acrítica.

\section{Referências bibliográficas}

ARAÚJO, Joel Zito. A negação do Brasil. O negro na telenovela brasileira. 2.ed. São Paulo: Senac, 2004.

. A força de um desejo - a persistência da branquitude como padrão estético audiovisual. Revista USP. Racismo II. São Paulo, n.69, p. 72-79, março/maio. 2006.

BAUMAN, Zygmunt. Identidade. Entrevista a Benedetto Vecchi. Rio de Janeiro: Jorge Zahar Ed, 2005.

BARBOSA, Luciene Cecília. As situações de racismo e branquitude representadas na telenovela "Da cor do pecado". In: XXVII CONGRESSO BRASILEIRO DE CIÊNCIAS DA COMUNICAÇÃO. 2004, Porto Alegre.

COUCEIRO DE LIMA, Solange M. O negro na televisão de São Paulo: um estudo de relações raciais. São Paulo, FFLCH/USP, 1983.

ENNE, Ana Lucia S. À perplexidade, a complexidade: A relação entre consumo e identidades nas sociedades contemporâneas. In: Comunicação, Mídia e Consumo. vol.3. $\mathrm{n}^{0}$.7. São Paulo: ESMP, 2006, p.11-29.

ESTEVES, João Pissarra. Os media e a questão da identidade. Sob as leituras pós-modernas do fim do sujeito. Universidade de Lisboa. mar. 1999. Disponível em: www.bocc.ubi.pt. Consultado em 19 abr. 2007.

FIGUEIRA, Vera Moreira. Preconceito racial: difusão e manutenção pela escola. Revista Intercâmbio. Rio de Janeiro, SESC. jan.abr. 1988, p.37-46.

HALL, Stuart. A identidade cultural na pós-modernidade. 3.ed. Rio de Janeiro: DP\&A, 1999.

. Da diáspora. Identidades e mediações culturais. Belo Horizonte: Humanitas, 2003.

KELLNER, Douglas. A cultura da mídia. Bauru, São Paulo: EDUSC, 2001. 
MARTÍN-BARBERO, Jesús. Dos meios às mediações. Comunicação, cultura e hegemonia. Rio de janeiro: Editora UFRJ, 1997.

MARTÍN-BARBERO, Jesús; REY, Germán. Los ejercicios del ver. Hegemonia audiovisual y ficción televisiva. Barcelona: Gedisa Editoral, 1999.

MOTTER, Maria Lourdes. Ficção e realidade: a construção do cotidiano na telenovela. São Paulo: Alexa Cultural, Comunicação \& Cultura _ Ficção Televisiva, 2003.

PACHECO, Dalmer Almeida. Telenovela: o (in)discreto charme da burguesia; desvios de conduta e merchandising de valores. Maceió: Edufal, 1988.

PALLOTTINI, Renata. Dramaturgia de televisão. São Paulo: Moderna, 1998.

PEREIRA, Edimilson de Almeida; GOMES, Núbia Pereira de Magalhães. Ardis da imagem: exclusão e violência nos discursos da cultura brasileira. Belo Horizonte: Mazza Edições, Editora PUC Minas, 2001.

SODRÉ, Muniz. Claros e escuros. Identidade, povo e mídia no Brasil. 2.ed. Petrópolis: Vozes, 1999.

Reinventando a cultura. A comunicação e seus produtos. Petrópolis: Vozes, 1997. 